\title{
Next Generation of Weight Management Medications: Implications for Diabetes and CVD Risk
}

\author{
S. Wharton • K. J. Serodio
}

Published online: 18 April 2015

(C) The Author(s) 2015. This article is published with open access at Springerlink.com

\begin{abstract}
Since the 1980s, the prevalence of obesity has almost doubled worldwide. Treatments for obesity include lifestyle modification, medications and surgery. Newer anti-obesity medications have been shown to be effective at inducing initial weight management in addition to successful long-term weight maintenance. Historically, weight management medications have been associated with public safety concerns that have resulted in the majority being withdrawn from the market or never receiving medicinal authorization. Recently, several countries have approved some newer generation weight management medications which may be beneficial to combat obesity. These medications have varying effects on cardiometabolic parameters, both positive and potentially negative. This review will outline the mechanisms of action of these medications and their implications for both diabetes and cardiovascular risks.
\end{abstract}

Keywords Weight management · Medications · Cardiometabolic risks

This article is part of the Topical Collection on Diabetes and Cardiovascular Disease

S. Wharton $(\bowtie) \cdot$ K. J. Serodio

Weight Management and Diabetes Management, The

Wharton Medical Clinic, 414 Victoria Ave N Suite 14,

Hamilton, ON L8L 5G8, Canada

e-mail: wharton.sean@gmail.com

K. J. Serodio

e-mail: kristinserodio@gmail.com

S. Wharton

Department of Health and Kinesiology, York University,

4700 Keele St, Toronto, ON M3J 1P3, Canada

\section{Introduction}

Overview and Prevalence

Since the 1980s, the prevalence of obesity has almost doubled worldwide, with over 500 million men and women being classified as obese [1]. Obesity is a condition characterized by excessive body fat and is often associated with pathophysiological complications to many endogenous systems including metabolic, cardiovascular, endocrine, central nervous and more [2]. Furthermore, obesity is a complex, chronic condition that is resistant to most standard treatments [3]. It is well established that a modest weight loss of 5 to $10 \%$ can decrease many weight-related cardiometabolic risk factors such as elevated glycaemic markers, abnormal blood lipids, increased uric acid concentrations and hypertension [4, 5]. Unfortunately, most patients have difficulty maintaining even this small amount of weight loss likely due to the activation of weight-preservation hormones and pathological changes to biological systems [3].

Weight management treatments focused on lifestyle intervention are generally linked with short-term weight loss followed by weight regain within 2 years $[4,6]$. Nonetheless, standard of treatment recommended for weight management is still lifestyle modification, with other measures such as pharmacological intervention and bariatric surgery acting as secondary and tertiary options [7]. Medications will be very useful to bridge the gap between lifestyle modifications and surgery and have been shown to increase the success of long-term weight maintenance. In the past 10 years, we have seen the development of several pharmacological agents for weight management [6]. These medications have beneficial effects on metabolic conditions such as diabetes, yet their effects on cardiovascular disease are still unclear. This review will outline the new generation of weight management medications and the implications for both diabetes and CVD. 
Pharmacotherapy Availability and Regulation

Although bariatric surgery has been shown to be a very effective weight management option, it is only offered to patients with a BMI $\geq 40 \mathrm{~kg} \mathrm{~m}^{2}$ or a BMI $\geq 35 \mathrm{~kg} \mathrm{~m}^{2}$ with one or more obesity-related comorbidity [6]. In contrast, weight management medications can be more widely prescribed to anyone with a BMI $\geq 30 \mathrm{~kg} \mathrm{~m}^{2}$ or those who have a BMI $>27 \mathrm{~kg} \mathrm{~m}^{2}$ with at least one obesity-related comorbidity $[8,9]$. Thus, pharmacotherapy treatment has the potential to be much more readily available to a greater proportion of persons with obesity.

Currently, there are three categories of anti-obesity drugs, including (1) central nervous system modifiers, (2) endocannabinoid inhibitors and (3) fat absorption inhibitors [4]. Prior to medicinal licencing and commercialization, medications must meet the guidelines by drug enforcement agencies such as Health Canada, the American Food and Drug Administration (FDA) and the European Medicines Agency (EMA). In past years, these agencies have limited the availability of anti-obesity medications due to public health concerns that frequently overshadow the relatively modest results received from pharmacotherapeutic treatment $[4,5]$.

\section{FDA Requirements for Approval of Anti-obesity Drugs}

Anti-obesity medication approval by the FDA requires a 24month study demonstrating a minimum $5 \%$ placebosubtracted weight loss and that at least $35 \%$ of the treatment group, or a significantly greater proportion of treatment subjects, maintain $\geq 5 \%$ weight loss from their initial body weight $[5,10]$. Similarly, the EMA guidelines require a $\geq 5 \%$ placebo-subtracted weight loss from baseline and recommend that trials at least 6 months in duration with one pivotal trial lasting $\geq 12$ months [11]. Medications are also expected to improve the body composition, health risk profile and health-related quality of life $(\mathrm{QoL})$ of patients as otherwise weight management would merely be for aesthetic purposes $[10,11]$. FDA and EMA medication approvals are usually accompanied by the requirement of post-marketing adverse event monitoring and cardiovascular risk research studies [6].

History and Cardiometabolic Consequences of Withdrawn Medications

Since the 1930s, the majority of anti-obesity medications that were once approved have been withdrawn from the market due to adverse effects and threat to public health [3, 7]. The side effect of these medications included disturbances to the psychological, central nervous and cardiovascular systems [3, $6,7]$. The once very popular sympathomimetic compounds ephedrine-alkaloids were withdrawn due to adverse cardiovascular events, including arrhythmias and sudden cardiac death $[12,13]$. Rimonabant (Acomplia $\left.{ }^{\circledR}\right)$, a selective cannabinoid (CB1) receptor inhibitor effective at decreasing appetite, was also withdrawn from the market due to doubling the risk of psychiatric disorders, in particular depression $[14,15]$. Fenfluramine-phentermine (Fen-Phen), a serotonin $\left(5 \mathrm{HT}_{-2 \mathrm{~b}}\right)$ receptor activator with sympathomimetic properties and anorectic actions, was removed from the market in 1997 due to valvular heart disease and pulmonary hypertension [16-18]. Similarly, sibutramine (Meridia ${ }^{\circledR}$ ) had sympathomimetic properties, inhibiting serotonin 5-HT reuptake, which helped to promote satiety, was also withdrawn in 2010 given its propensity to increase blood pressure, myocardial infarction and stroke risk, primarily in patients with existing CVD [18, 19]. The tendency for increased risk of cardiac events with the use of older antiobesogenics is well established while the cardiometabolic effects of newer generation anti-obesogenics is still being investigated.

\section{Weight Management Medications}

Orlistat $\left(\right.$ Xenical $^{\circledR}$, Alli $\left.^{\circledR}\right)$

Orlistat is a pancreatic lipase inhibitor that decreases the absorption of dietary fats $[4,20]$. Long-term medicinal treatment is associated with a dose-dependent 2.5 to $3.4 \mathrm{~kg}, 3.1 \%$, placebo-subtracted weight loss (Fig. 1) [20-22].

Cardiometabolic implications: Cardiometabolic risk factors such as total cholesterol (TC), low-density lipoprotein (LDL) cholesterol as well as systolic and diastolic blood pressure (BP) have all been noted to improve with long-term use (Table 1) [15, 21-23]. However, there have been no hard endpoint cardiovascular disease reductions with this medication, and long-term ( $\geq 1$ year) patient discontinuation rates are high at approximately $90 \%$ due to it being commonly linked

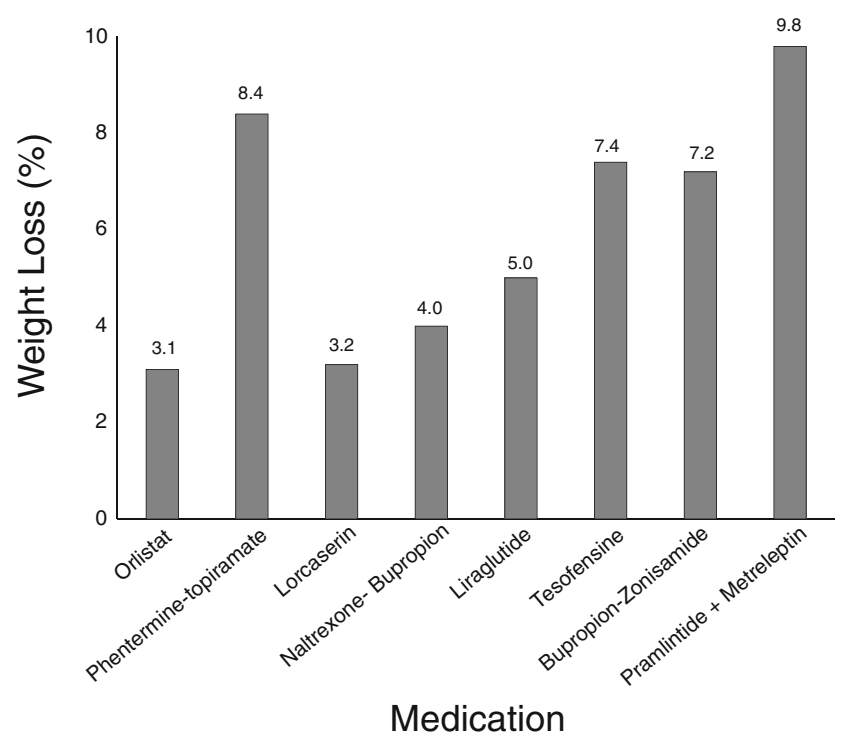

Fig. 1 Average placebo-subtracted weight loss (\%) 


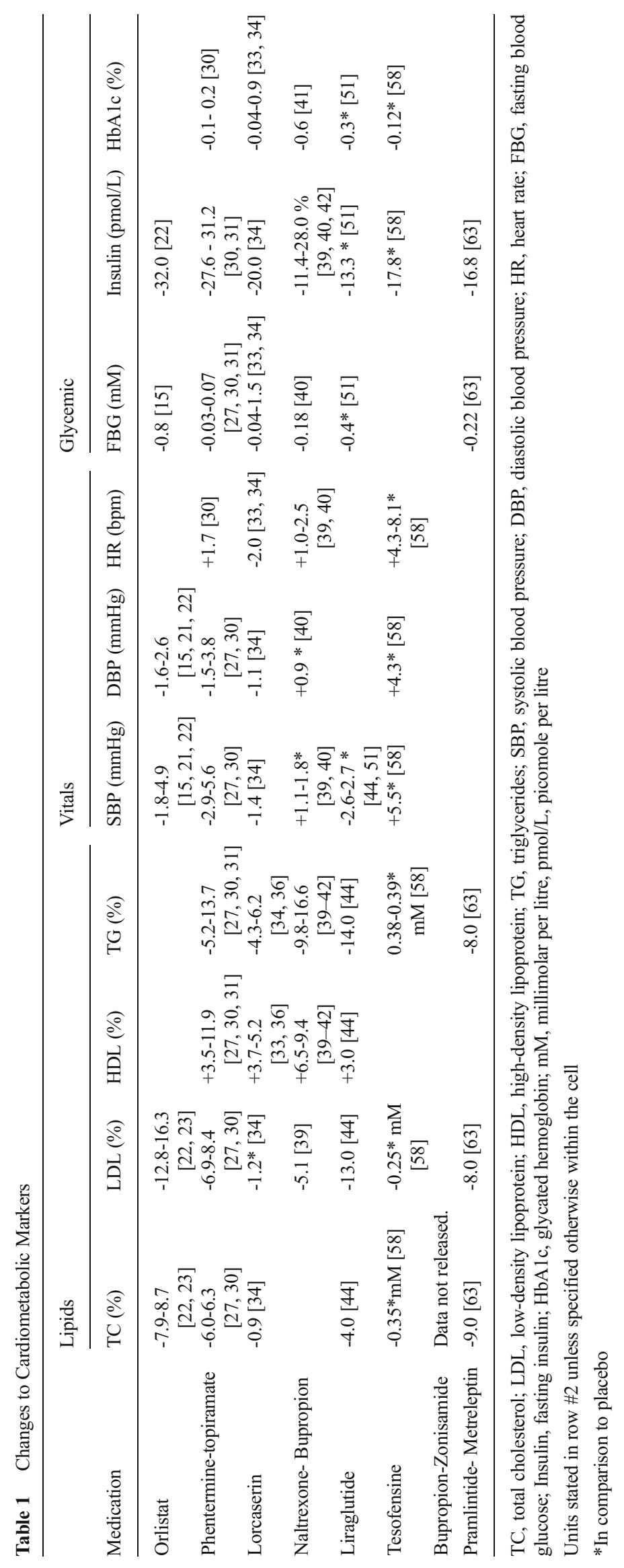


with the malabsorption of fat-soluble vitamins, abdominal bloating, gastric pain and unpleasant steatorrhoea [10, 20].

Diabetic implications: The Xendos trial was one of the first studies with a weight management medication designed to demonstrate prevention of progression to diabetes in prediabetic patients [22]. This was a positive trial demonstrating a $37.3 \%$ decrease in progression to diabetes [22]. The American Heart Association (AHA), American College of Cardiology (ACC), Endocrine Society and the Canadian Diabetes Association (CDA) guidelines all suggest orlistat as an effective therapy to assist in optimizing glycaemic markers and/or manage weight in patients with and without diabetes [24-26].

Phentermine-Topiramate $\left(\right.$ Qsymia $^{\circledR}$, Qnexa $^{\circledR}$, Qsiva $\left.^{\circledR}\right)$

Phentermine-topiramate controlled-release compounds help to suppress appetite [3]. Phentermine has been used for weight management in the USA for decades, but is rarely used in Canada and is off the market in Europe [6, 27]. Phentermine suppresses appetite through amphetamine effects [3]. Topiramate is indicated as an anti-epileptic medication that has also been associated with weight loss [3, 18, 27, 28•]. Topiramate's mechanism for weight management is unclear $[3,18,27]$. Yet, both increased resting energy expenditure and anorectic properties may be causative [3, 26, 27]. The combination medication uses lower doses of each medication resulting more mild side effects than would be seen at usual doses [18]. Qsymia ${ }^{\circledR}$ was recently approved in the USA in 2012 but is yet to be approved by the Health Canada and EMA [3, 29]. Phentermine-topiramate FDA approval was primarily based on four studies that lasted between 24 and 56 weeks [7]. The EQUATE, EQUIP, CONQUER and SEQUEL trials reported placebo-subtracted weight losses of approximately 7.4 to $10.8 \mathrm{~kg}$ or between 7.5 and $9.3 \%$ (Fig. 1) [3, 27, 30, 31]. Mild adverse events commonly linked with phentermine-topiramate include paresthesia, palpitations and elevated heart rate, while serious harms include an increased probability of cognitive deficits, metabolic acidosis and increased risk of birth defects [6, 20, 28•].

Cardiac implications: In the pivotal trials, phenterminetopiramate use was associated with improvements in surrogate cardiac markers including TC, LDL, high-density lipoprotein (HDL), triglycerides (TGs), BP, inflammatory markers and a reduction in the number of hypertensive medications patients required [27, 30, 31]. Conversely, phentermine-topiramatetreated subjects showed an elevated heart rate of 1.2 to 1.7 beats per minutes (bpm), in comparison to placebo subjects (Table 1) [27, 30, 31]. When submitting for FDA approval, preliminary major adverse cardiovascular events (MACE) data was reviewed and it was determined that there was no significant difference in the risk of cardiovascular death, nonfatal myocardial infarction and non-fatal stroke between phentermine-topiramate and placebo [28•]. That being said, cardiac safety analysis was not the primary goal of past studies and many were underpowered [28•]. The Endocrine Society's Pharmacological Management of Obesity guidelines specify that, due to their sympathomimetic properties, phenterminecontaining compounds should be not be prescribed to patients with a history of heart disease and uncontrolled hypertension until more detailed cardiac safety data is obtained [26]. The promise of a future cardiovascular event-specific trial called Aqclaim was a condition of FDA approval and will be beneficial in assisting both Health Canada and the EMA in making a firm decision on the safety of phenterminetopiramate therapy [28•, 32].

Diabetes implications: Phentermine-topiramate use is associated with improvements to numerous glycaemic markers such FBG, fasting insulin, glycated haemoglobin (HbA1c) and homeostatic model assessment of insulin resistance (HOMA-IR) (Table 1) [27, 30, 31]. Diabetic and prediabetic patients using phentermine-topiramate not only achieved clinically significant weight loss but also required fewer additional anti-diabetic drugs when compared against non-users [30]. Over a 2-year trial period, the significant weight loss associated with phentermine-topiramate use in non-diabetic patients slowed the progression of type 2 diabetes by $54 \%[31]$.

\section{Lorcaserin (Belviq ${ }^{\circledR}$ )}

Another newly approved medication by the FDA, in 2012, is Belviq ${ }^{\circledR}$. Lorcaserin is a selective serotonin $2 \mathrm{c}\left(5 \mathrm{HT}_{-2 \mathrm{c}}\right)$ receptor activator that promotes appetite suppression [7]. Lorcaserin is theorized to reduce energy intake through influencing the hypothalamic pro-opiomelanocortin (POMC) neurons within the central nervous system [7, 33, 34]. Health Canada approval is still pending, and EMA authorization was denied given the unexplained increase in various cancers seen in rodent studies and the potential risk for valvular pathology, although neither have been seen in human studies to date $[3,6$, 35]. Three trials are commonly referenced when assessing the long-term effects of lorcaserin, BLOOM, BLOSSOM AND BLOOM-DM [33, 34, 36]. On average, a $3.2 \mathrm{~kg}$, or $3.2 \%$, placebo-subtracted weight loss is expected with long-term ( $\geq 1$-year) use, whereas shorter programmes between 8 and 12 weeks promote placebo-subtracted weight losses of 1.6 to $2.9 \mathrm{~kg}$ (Fig. 1) [7, 33, 34, 36]. Within the trials, the statistically significant placebo-subtracted percent weight loss from baseline ranged between 3.0 and $3.6 \%$, which is below the desired $5 \%[33,34,36]$. Nevertheless, approximately double the number of participants was able to attain a $\geq 5 \%$ statistically significant weight loss in comparison to placebo (Table 2) [33, 34, 36]. Mild adverse events associated with lorcaserin use include headache, dizziness and nausea $[3,7]$. 
Table 2 Proportion of participants expected to lose $\geq 5 \%$

\begin{tabular}{|c|c|c|c|}
\hline Medication & Intervention & Placebo & Difference \\
\hline \multicolumn{4}{|l|}{ Orlistat } \\
\hline Torgerson 2004 & 72.8 & 45.1 & 27.7 \\
\hline \multicolumn{4}{|c|}{ Phentermine-topiramate } \\
\hline Allison 2012 & 66.7 & 17.3 & 49.4 \\
\hline Gadde 2011 & 70.0 & 21.0 & 49.0 \\
\hline Garvey 2012 & 79.3 & 30.0 & 49.3 \\
\hline Average & 72.0 & 22.8 & 49.2 \\
\hline \multicolumn{4}{|l|}{ Lorcaserin } \\
\hline Smith 2010 & 47.5 & 20.3 & 27.2 \\
\hline Fidler 2011 & 47.2 & 25.0 & 22.2 \\
\hline O'neil 2012 & 37.5 & 16.1 & 21.4 \\
\hline Average & 44.07 & 20.5 & 23.6 \\
\hline \multicolumn{4}{|c|}{ Naltrexone-bupropion } \\
\hline Wadden 2011 & 66.4 & 42.5 & 23.9 \\
\hline Greenway 2010 & 48.0 & 16.0 & 32.0 \\
\hline Apovian 2013 & 50.5 & 17.1 & 33.4 \\
\hline Hollander 2013 & 44.5 & 18.9 & 25.6 \\
\hline Average & 52.4 & 23.6 & 28.7 \\
\hline \multicolumn{4}{|l|}{ Liraglutide } \\
\hline Astrup 2009 & 76.1 & 29.6 & 46.5 \\
\hline Wadden 2013 & 50.5 & 21.8 & 28.7 \\
\hline Average & 63.3 & 25.7 & 37.6 \\
\hline \multicolumn{4}{|l|}{ Tesofensine } \\
\hline Astrup 2008 & 91.0 & 29.0 & 62.0 \\
\hline \multicolumn{4}{|c|}{ Bupropion-zonisamide } \\
\hline Orexigen 2014 & 82.6 & 18.9 & 63.7 \\
\hline \multicolumn{4}{|c|}{ Pramlintide-metreleptin } \\
\hline Ravussin 2009 & 89.0 & $-^{\mathrm{a}}$ & $-^{\mathrm{a}}$ \\
\hline
\end{tabular}

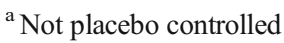

Cardiac implications: With long-term, twice daily, lorcaserin treatment TC, LDL, HDL, TGs, BP and heart rate (HR) all significantly improved (Table 1) $[33,34,36]$. As a result of the valvular complications associated with previous selective serotonin receptor activators, lorcaserin trials are obligated to include echocardiograms which to date have not documented any differences in valvular function $[3,6,36]$. The Endocrine Society recommends its use in patients with a history of heart disease over medications that have sympathomimetic effects [26]. Although lorcaserin treatment has been associated with a number of beneficial cardiometabolic improvements, the majority of trials have been of homogeneous populations and too underpowered to statistically test for echocardiographic safety $[3,33,34,36]$. So, future research will be required before these findings can be generalized across ethnicities and gender. The FDA-requested cardiovascular safety trial for lorcaserin is called Camellia [37]. The 5-year multicenter TIMI study started recruiting in late 2013 and will include approximately 12,000 patients in 14 countries around the world [37].

Diabetes implications: For both diabetic and non-diabetic patients, lorcaserin treatment resulted in improvements in numerous glycaemic markers such FBG, fasting insulin, $\mathrm{HbA1c}$ and HOMA-IR (Table 1) [33, 34]. Lorcaserin-treated patients were also significantly less likely to have to increase their antidiabetic medications when compared against non-users over a 1 -year period [33]. The positive glycaemic influence of lorcaserin is likely weight dependent given that after 2 years of treatment some weight regain occurred, which consequently removed the beneficial effects of lorcaserin on glucose and insulin concentrations $[6,34]$.

\section{Naltrexone-Bupropion (Contrave ${ }^{\circledR}$ )}

In the fall of 2014, FDA approval was given to an anorectic combination medication, of naltrexone and bupropion, called Contrave $^{\circledR}\left[38^{\circ}\right]$. Naltrexone and bupropion are both used in the treatment of addiction [39, 40]. Mechanistically, the bupropion component of this combination therapy is thought to stimulate POMC neurons while naltrexone inhibits the opioid-mediated area of the POMC system [40]. Additionally, both drugs are believed to influence the mesolimbic dopaminergic reward system [41]. Six months of naltrexone-bupropion combination therapy is associated with a 3.8 to $4.9 \mathrm{~kg}$, or 3.2 to $4.8 \%$, placebo-subtracted weight loss and 23 to $33 \%$ more patients attaining a $\geq 5 \%$ weight loss (Fig. 1 and Table 2) [3, 39-42]. Common minor adverse reactions associated with Contrave use include nausea, bowel/ digestive upset, insomnia and headaches $[38 \bullet, 40]$. Some major adverse reactions include increased risk of neuropsychiatric events and increased risk of seizures [38•].

Cardiometabolic implications: Improvements to QoL and several cardiometabolic risk factors such as LDL, HDL and TGs have been linked with naltrexone-bupropion treatment [39-42]. Unfortunately, in comparison to placebo, naltrexone-bupropion use has been linked with a significantly smaller decrease in BP by 0.9 to $1.8 \mathrm{mmHg}$ and elevated heart rate (Table 1) [39, 40]. Based on the recommendations from the Endocrine Society to avoid agents with sympathomimetic properties, naltrexone-bupropion should likely not be used as a first-line medication for patients with a history of cardiac dysfunction [26]. Electrocardiographic findings after more than 1 year of medicinal treatment did not find any differences between treatment and placebo [40]. Yet, the long-term consequences of the aforementioned increases in BP and HR with Contrave use are ambiguous so the FDA stipulated that additional cardiovascular safety outcomes are required. Thus, a long-term cardiovascular safety trial called 'the Light Study' is under way and should be completed by mid-2017 [3].

Diabetic implications: In non-diabetic patients, naltrexonebupropion has been linked to a positive influence on FBG, 
fasting insulin, HbA1c and HOMA-IR without significantly increasing the prevalence of hypoglycaemic events [39-42]. Naltrexone-bupropion use in diabetic patients demonstrated beneficial effects on HbA1c levels and HbAlc goal attainment which ultimately resulted in significantly fewer participants requiring an increase in diabetic medications over 56 weeks of treatment (Table 1) [41]. It should be noted that the naltrexone-bupropion trials lacked heterogeneity as the vast majority of studies included white women without considerable co-morbidities (diabetes, cardiovascular disease) [39, 40, 42].

\section{Liraglutide (Saxenda ${ }^{\circledR}$ )}

GLP-1R agonists, such as liraglutide, enhance insulin sensitivity, suppress appetite and delay gastric emptying [43]. Liraglutide works to stimulate the release of insulin from beta cells and suppresses glucagon secretion from alpha cells when blood glucose levels are elevated [44]. In 2009 and 2010, the FDA, EMA and Health Canada approved the use of liraglutide 0.6 to $1.8 \mathrm{mg}$ for the treatment of type 2 diabetes $[45,46]$. In December 2014 the FDA approved the use of liraglutide $3.0 \mathrm{mg}$ for the treatment of obesity, shortly followed by Health Canada's approval in February 2015 [47••, 48]. The trade name for liraglutide $3.0 \mathrm{mg}$ is Saxenda ${ }^{\circledR}[47 \bullet \bullet]$. The four trials frequently referenced when assessing the effects of liraglutide $3.0 \mathrm{mg}$ are the SCALE, SCALE-Maintenance, SCALE-OSA and SCALE-Diabetes trials [49]. Liraglutide $3.0 \mathrm{mg}$-treated patients generally achieved a 4.4 to $5.9 \mathrm{~kg}$ or 3.9 to $6.1 \%$ greater weight loss than placebo groups (Fig. 1) [44, 50, 51••]. Moreover, liraglutide $3.0 \mathrm{mg}$ resulted in 29 to $47 \%$ more of the liraglutide participants attaining a $\geq 5 \%$ weight loss when compared against placebo participants and $32.5 \%$ more being able to maintain significant weight loss after a lifestyle intervention (Table 2) [50, 51••]. Liraglutide was not only more effective at weight loss maintenance but also stimulated an additional $6.0 \%$ greater weight loss than control groups in 56 weeks of medicinal treatment postlifestyle intervention [51••]. Gastrointestinal upset such as nausea, vomiting and diarrhoea are the most frequent adverse events associated with liraglutide use [44, 50, 51••].

Cardiometabolic implications: The cardiovascular improvements associated with liraglutide $3.0 \mathrm{mg}$ use include decreased TC, LDL, HDL, TGs and SBP (Table 1) [44, $51 \bullet \bullet$. The cardioprotective effectives of liraglutide in lower doses (1.2/1.8 mg, etc.) have been consistently demonstrated [43, 52-56]. These results must be taken with a degree of scepticism given that long-term cardiometabolic safety information at the 3.0-mg dosage proposed for weight management is not currently available. More informative cardiovascular safety data is expected by mid-2016 with the completion of the "Liraglutide Effect and Action in Diabetes: Evaluation of Cardiovascular Outcome Results (LEADER)" trial [56].
Diabetes implications: The SCALE-Maintenance trial looked at the influence of liraglutide $3.0 \mathrm{mg}$ throughout a 56-week intervention, and as expected, liraglutide users had significantly improved FBG, fasting insulin and HbA1c measurements when compared against placebo participants (Table 1) [51••]. Furthermore, this trial noted that fewer liraglutide $3.0 \mathrm{mg}$ users had to withdraw from their intervention due to type 2 diabetes onset when compared against nonusers [51••]. Given that GLP-1R agonists are associated with not only successful weight loss but also glycaemic control, the Endocrine Society has suggested that they can be used as a first-line agent or an add on to other therapies for patients with diabetes [26]. To date, results indicate that liraglutide is effective at decreasing the weight and glycaemic markers of overweight and obese diabetic patients without substantially increasing the risk of hypoglycaemic events [44].

\section{Pipeline Medications}

\section{Tesofensine}

Originally produced as an Alzheimer's disease treatment, tesofensine inhibits norepinephrine, serotonin and dopamine reuptake [10]. It was not found to improve Alzheimer's disease but did result in substantial weight loss in a considerable number of patients [10]. Tesofensine was soon found to have anorectic properties in addition to the potential to increase energy expenditure $[10,57,58]$. Consequently, weight management trails were carried out, and they documented dosedependent weight losses of 4.5 to $10.6 \mathrm{~kg}$, or 4.4 to $10.4 \%$, of participants' initial body weight with 59 to $91 \%$ of patients achieving a $\geq 5 \%$ weight loss (Fig. 1 and Table 2) [58]. Adverse events associated with its use include dry mouth, nausea and constipation [58].

Cardiometabolic implications: After 24 weeks, at various doses, of tesofensine use, TC, LDL and TG levels improved in non-diabetic participants [58]. Regrettably, increases to hemodynamic measurements such as BP and HR also occurred with tesofensine, and a small amount of weight regain occurred after medication discontinuation (Table 1) [58].

Diabetes implications: Tesofensine has been found to have beneficial effects on plasma insulin and $\mathrm{HbA} 1 \mathrm{c}$ concentrations (Table 1) [58]. However, there is very limited data to substantiate these findings as the majority of trials have been completed on rodents, are not published in English or are methodologically flawed [57].

Bupropion-Zonisamide Slow-Release Compound (Empatic ${ }^{\circledR}$ )

A bupropion-zonisamide slow-release compound, Empatic ${ }^{\circledR}$, is undergoing FDA phase III clinical development [59, 60]. Bupropion is an antidepressant and smoking cessation drug 
that stimulates norepinephrine and dopamine activity [61]. Zonisamide is indicated as an anti-epileptic drug with mechanisms that influence serotonin and dopamine [61]. Together, bupropion-zonisamide has the potential to influence all three major neurotransmitters that regulate energy expenditure and appetite [61]. Previous trials document bupropion-zonisamide use to result in a $7.2 \%$ placebo-subtracted reduction in weight from baseline with $63 \%$ more of the medicinal users losing $\geq 5 \%$ of their initial body weight (Fig. 1 and Table 2) [10, 60, $62 \bullet \cdot$. Bupropion and zonisamide have been combined not only due to their anorectic properties but also due to the offsetting adverse effect profile of each medication [61]. Bupropion monotherapy is characterized by psychomotor agitation and insomnia while zonisamide use is associated with somnolence, psychomotor inhibition, teratogenicity and depression [61]. In comparison to monotherapy, bupropionzonisamide use has a more mild adverse reaction profile inclusive of headaches, nausea and insomnia $[4,60]$.

Cardiovascular implications: Preliminary data claims that combination therapy is positively associated with improvements in TGs and BP, but available data is extremely limited with only an overview of results being released by the manufacturer (Orexigen) $[10,62 \bullet \bullet]$.

Diabetes implication: Bupropion-zonisamide treatment has also been linked to decreased fasting insulin, but currently, there is not enough available research to confirm its cardiometabolic safety profile.

\section{Pramlintide + Metreleptin (Amylin/Leptin)}

Pramlintide is an amylin synthetic analog that is hypothesized to influence amylin receptor activation in order to produce a satiating effect, reduce food intake and regulate short-term energy homeostasis $[10,63,64]$. Metreleptin is a leptin analog that has the potential to influence the hypothalamus in order to help regulate hunger cues and long-term energy homeostasis $[10,63,64]$. Thus far, there is a limited number of human trials evaluating the influence of amylin/leptin, although rodent trials indicate a synergistic effect that results in successful body weight reductions and improvements in cardiometabolic parameters $[10,64]$. A human trial that looked at severe dietary restriction (up to $45 \%$ ) in addition to either combination therapy or monotherapy leads to a $11.5 \mathrm{~kg}, 12.7 \%$, reduction in initial body weight in the combination group in comparison to $7.4 \mathrm{~kg}(8.4 \%)$ and $7.9 \mathrm{~kg}(8.2 \%)$ reduction in the pramlintide and metreleptin monotherapy groups, respectively (Fig. 1) [63]. A phase 2 clinical trial in humans also documented a $9.2 \%$ placebo-subtracted weight loss after 28 weeks of treatment [65]. The most common mild adverse events linked with amylin/ leptin treatment are nausea and injection site irregularities [63].

Cardiometabolic implications: For patients with baseline normoglycaemic and lipidaemic measurements, amylin/ leptin treatment resulted in decreased TC, LDL and TGs (Table 1) [63].

Diabetes implications: Amylin/leptin use has also been connected with beneficial influences on glycaemic markers such as FBG, insulin and HOMA-IR (Table 1) [63]. However, the two companies coordinating the preliminary trails for amylin/leptin completed a commercial assessment that ended in the decision to halt future research [64] which disallows any firm conclusions to be made in regard to the efficacy and cardiometabolic safety of this type of medication.

\section{Conclusion}

In summary, the newer generation anti-obesogenic medications reviewed in this study frequently resulted in placebo-subtracted weight losses of approximately 3.0 to $9.0 \mathrm{~kg}$. Although this may not seem like a large amount of weight loss, these results are substantially better than the average 2.0 to $3.0 \mathrm{~kg}$ of weight loss attained through 36 months of lifestyle intervention [18]. It is important to note that weight management medications are not linked with any permanent biological changes to mechanisms associated with obesity and as such do not generally have lasting weight loss effects after medicinal treatment has ceased [26]. This is problematic given that historically long-term ( $>2$ years) adherence for weight management medications is minimal at approximately $2 \%$ [3].

Newer generation anti-obesity agents have been associated with a multitude of cardioprotective effects and favourable glycaemic results which have lead to FDA approval of quite a few new obesity medications. Before patients begin pharmacological therapy, current health status, medication usage, medical history and regional approval all need to be considered. In concordance with the Endocrine Society, we recommend that for patients with a history of cardiovascular dysfunction or uncontrolled hypertension, non-sympathomimetic agents such as lorcaserin or orlistat be used as a first-line therapy in the pharmacological treatment of obesity. For patients with diabetes, GLP-1 agonists that have consistently documented positive glycaemic effects should be initially prescribed. Patients with both CVD and diabetes may also do well on liraglutide given its history of cardiac safety at lower doses in addition to the cardiometabolic improvements seen in recent literature. Overall, the beneficial cardiometabolic influences anti-obesogenic agents have largely not been assessed long term, with very little available data supporting reductions in long-term MACEs and mortality. In order to bridge these obvious gaps, heterogeneous longitudinal studies are required. Clinically, these results are promising, but as with any medication, the adverse events associated with their use must be kept in mind. Thus, when prescribing anti-obesogenic agents, health care providers should take care to properly monitor patients and cease medicinal treatment if the expected 
reductions in weight and cardiometabolic risk factors are not obtained within a reasonable period of time.

\section{Compliance with Ethics Guidelines}

Conflict of Interest S. Wharton and K.J. Serodio declare that they have no conflict of interest.

Human and Animal Rights and Informed Consent This article does not contain any studies with human or animal subjects performed by any of the authors.

Open Access This article is distributed under the terms of the Creative Commons Attribution License which permits any use, distribution, and reproduction in any medium, provided the original author(s) and the source are credited.

\section{References}

Papers of particular interest, published recently, have been highlighted as:

- Of importance

•- Of major importance

1. WHO. Obes. Overweight fact sheet. 2013. Available at: http:// www.who.int/mediacentre/factsheets/fs $311 /$ en/. Accessed 16 Oct 2014.

2. Herouvi D, Karanasios E, Karayianni C, et al. Cardiovascular disease in childhood: the role of obesity. Eur J Pediatr. 2013;172:72132.

3. Rueda-Clausen CF, Padwal RS, Sharma AM. New pharmacological approaches for obesity management. Nat Rev Endocrinol. 2013;9:467-78.

4. Carter R, Mouralidarane A, Ray S, et al. Recent advancements in drug treatment of obesity. Clin Med. 2012;12:456-60.

5. Halford JCG. Pharmacotherapy for obesity. Appetite. 2006;46:610 .

6. Manning S, Pucci A, Finer N. Pharmacotherapy for obesity: novel agents and paradigms. Ther Adv Chronic Dis. 2014;5:135-48.

7. Chan EW, He Y, Chui CSL, et al. Efficacy and safety of lorcaserin in obese adults: a meta-analysis of 1-year randomized controlled trials (RCTs) and narrative review on short-term RCTs. Obes Rev. 2013;14:383-92.

8. Orexigen Therapeutics Inc. Orexigen press release 2013Contrave and Empatic. 2013. 1-5. Available at: http://ir.orexigen. com/phoenix.zhtml? $\mathrm{c}=207034 \& \mathrm{p}=$ irol-newsArticle $\& I D=$ 1817249. Accessed 27 Oct 2014.

9. FDA. Contrave (naltrexone sr/bupropion SR combination): Advisory Committee Briefing Document. 2010;1-278.

10. Kennett GA, Clifton PG. New approaches to the pharmacological treatment of obesity: can they break through the efficacy barrier? Pharmacol Biochem Behav. 2010;97:63-83.

11. EMA. Guideline on clinical evaluation of medicinal products used in weight control. 2014;4:1-11.

12. FDA. Ephedrine alkaloid-containing dietary supplements. 2003. Available at: http://www.fda.gov/newsevents/testimony/ ucm115044.htm. Accessed 2 Oct 2014.

13. Andraws R, Chawla P, Brown DL. Cardiovascular effects of ephedra alkaloids: a comprehensive review. Prog Cardiovasc Dis. $2005 ; 47: 217-25$.
14. EMA. Press release: the European Medicines Agency recommends suspension of the marketing authorisation of Acomplia. 2008;4-5.

15. Padwal RS, Majumdar SR. Drug treatments for obesity: orlistat, sibutramine, and rimonabant. Lancet. 2007;369:71-7.

16. Connolly H, Crary J, McGoon M, et al. Vaulvular heart disease associated with fenfluramine-phentermine. N Engl J Med. 1997;337:581-8.

17. Sweeting AN, Tabet E, Caterson ID, et al. Management of obesity and cardiometabolic risk - role of phentermine / extended release topiramate. Diabetes Metab Syndr Obes. 2014;12:35-44.

18. Hainer V, Hainerová IA. Do we need anti-obesity drugs? Diabetes Metab Res Rev. 2012;28 Suppl 2:8-20.

19. EMA. European Medicines Agency recommends suspension of marketing authorisations for sibutramine. 2010;44:1-2.

20. Yanovski S, Yanovski JA. Long-term drug treatment for obesity: a systematic and clinical review. JAMA. 2014;311:74-86.

21. Sumithran P, Proietto J. Benefit-risk assessment of orlistat in the treatment of obesity. Drug Saf. 2014;37:597-608.

22. Torgerson J, Hauptman J, Boldrin M, et al. XENical in the prevention of diabetes in obese subjects (XENDOS) study: a randomized study of orlistat as an adjunct to lifestyle changes for the prevention of type 2 diabetes in obese patients. Diabetes Care. 2004;27:15561.

23. Erdmann J, Lippl F, Klose G, et al. Cholesterol lowering effect of dietary weight loss and orlistat treatment - efficacy and limitations. Aliment Pharmacol Ther. 2004;19:1173-9.

24. Ransom T, Goldenberg R, Mikalachki A, et al. Reducing the risk of developing diabetes. Can J diabetes. 2013;37 Suppl 1:S16-9.

25. Jensen MD, Ryan DH, Apovian CM, et al. 2013 AHA/ACC/TOS guideline for the management of overweight and obesity in adults: a report of the American College of Cardiology/American Heart Association Task Force on Practice Guidelines and The Obesity Society. Circulation. 2014;129:S102-38.

26. Apovian CM, Aronne LJ, Bessesen DH, et al. Pharmacological management of obesity: an endocrine society clinical practice guideline. J Clin Endocrinol Metab. 2015.

27. Allison DB, Gadde KM, Garvey WT, et al. Controlled-release phentermine/topiramate in severely obese adults: a randomized controlled trial (EQUIP). Obesity (Silver Spring). 2012;20:330-42.

28. FDA. New Drug Application 22580- VI-0521 QNEXA (phentermine/topiramate). 2012;1-200. This report summarized MACE data and it was determined that there was no significant difference in the risk of cardiovascular death, non-fatal myocardial infarction and non-fatal stroke between phentermine-topiramate and placebo.

29. Woloshin S, Schwartz L. The new weight-loss drugs, lorcaserin and phentermine-topiramate: slim pickings? JAMA Intern Med. 2014;174:615-9.

30. Gadde KM, Allison DB, Ryan DH, et al. Effects of low-dose, controlled-release, phentermine plus topiramate combination on weight and associated comorbidities in overweight and obese adults (CONQUER): a randomised, placebo-controlled, phase 3 trial. Lancet. 2011;377:1341-52.

31. Garvey WT, Ryan DH, Look M, et al. Two-year sustained weight loss and metabolic benefits with controlled-release phentermine / topiramate in obese and overweight adults (SEQUEL): a randomized, placebo-controlled, phase 3 extension study 1-3. 2012;297308.

32. VIVUS. VIVUS Updates European Filing Strategy for Qsiva. 2013. 1-2. Available at: http://ir.vivus.com/releasedetail.cfm? ReleaseID=791927. Accessed 2 Oct 2014.

33. O'Neil PM, Smith SR, Weissman NJ, et al. Randomized placebocontrolled clinical trial of lorcaserin for weight loss in type 2 diabetes mellitus: the BLOOM-DM study. Obesity. 2012;20:1426-36.

34. Smith SR, Weissman NJ, Anderson CM, et al. Multicenter, placebo-controlled trial of lorcaserin for weight management. N Engl J Med. 2010;363:245-56. 
35. EMA. Assessment report-Belviq. 2013;44:1-43.

36. Fidler MC, Sanchez M, Raether B, et al. A one-year randomized trial of lorcaserin for weight loss in obese and overweight adults: the BLOSSOM trial. J Clin Endocrinol Metab. 2011;96:3067-77.

37. Eisai. Eisai Begins CAMELLIA-TIMI 61 LT outcomes study to assess cardiometa effects of lorcaserin HCI CIV in OW and OB pts. 2014;1-5. Available at: http://eisai.mediaroom.com/2014-0224-Eisai-Begins-CAMELLIA-TIMI-61-Long-term-OutcomesStudy-to-Assess-Cardiovascular-and-Metabolic-Effects-ofLorcaserin-HCI-CIV-in-Overweight-Obese-Patients. Accessed 28 Nov 2014.

38. FDA. FDA approves weight-management drug Contrave. 2014;1-4. Available at: http://www.fda.gov/NewsEvents/Newsroom/ PressAnnouncements/ucm413896.htm. Accessed 31 Oct 2014. This webpage provided some of the latest breaking news on Contrave FDA Approval. It also provided useful, publically available, information on study results and medication contraindications.

39. Apovian CM, Aronne L, Rubino D, et al. A randomized, phase 3 trial of naltrexone SR/bupropion SR on weight and obesity-related risk factors (COR-II). Obesity. 2013;21:935-43.

40. Greenway FL, Fujioka K, Plodkowski RA, et al. Effect of naltrexone plus bupropion on weight loss in overweight and obese adults (COR-I): a multicentre, randomised, double-blind, placebo-controlled, phase 3 trial. Lancet. 2010;376:595-605.

41. Hollander P, Gupta A, Plodkowski R, et al. Effects of naltrexone sustained-release/bupropion sustained-release combination therapy on body weight and glycemic parameters in overweight and obese patients with type 2 diabetes. Diabetes Care. 2013;36:4022-9.

42. Wadden TA, Foreyt JP, Foster GD, et al. Weight loss with naltrexone SR/bupropion SR combination therapy as an adjunct to behavior modification: the COR-BMOD trial. Obesity. 2011;19:110-20.

43. Marre M, Shaw J, Brändle M, et al. Liraglutide, a once-daily human GLP-1 analogue, added to a sulphonylurea over 26 weeks produces greater improvements in glycaemic and weight control compared with adding rosiglitazone or placebo in subjects with type 2 diabetes (LEAD-1 SU). Diabet Med. 2009;26:268-78.

44. Novo Nordisk. Phase 3a liraglutide $3 \mathrm{mg}$ trial demonstrated significant weight loss and improved cardiovascular risk factors in adults with obesity and type 2 diabetes compared with placebo. 2014;1-4.

45. FDA. Highlight of prescribing information Victoza. 2010;1-23.

46. FDA. Approved diabetes medicines. 2014;1-4. Available at: http:// www.fda.gov/forpatients/illness/diabetes/ucm408682. htm\#collapse3. Accessed 29 Oct 2014

47.• FDA. FDA approves weight-management drug Saxenda. 2014. Available at: http://www.fda.gov/NewsEvents/Newsroom/ PressAnnouncements/ucm427913.htm. Accessed 16 Mar 2015. This report concisely outlined the FDA approval of Saxenda.

48. Novo Nordisk. Novo Nordisk receives Health Canada approval for Saxenda ${ }^{\circledR}$ (liraglutide) for the treatment of chronic weight management. Available at: http://www.newswire.ca/en/story/1494067/ novo-nordisk-receives-health-canada-approval-for-saxendaliraglutide-for-the-treatment-of-chronic-weight-management\#. Accessed 13 Mar 2015.

49. Novo Nordisk. Novo Nordisk reports $8 \%$ weight loss in phase $3 \mathrm{a}$ obesity trial with liraglutide $3 \mathrm{mg}$. 2013;24-26.

50. Astrup A, Rössner S, Van Gaal L, et al. Effects of liraglutide in the treatment of obesity: a randomised, double-blind, placebocontrolled study. Lancet. 2009;374:1606-16.

51.• Wadden T, Hollander P, Klein S, et al. Weight maintenance and additional weight loss with liraglutide after low-calorie-dietinduced weight loss: the SCALE Maintenance randomized study. Int J Obes (Lond). 2013;37:1443-51. This SCALE trial found numerous positive cardiometabolic effects of liraglutide $3.0 \mathrm{mg}$ and is one of the defining studies used to assess the safety of liraglutide for weight management.

52. Nauck M, Frid A, Hermansen K, et al. Efficacy and safety comparison of liraglutide, glimepiride, and placebo, all in combination with metformin, in type 2 diabetes: the LEAD (liraglutide effect and action in diabetes)-2 study. Diabetes Care. 2009;32:84-90.

53. Garber A, Henry R, Ratner R, et al. Liraglutide versus glimepiride monotherapy for type 2 diabetes (LEAD-3 Mono): a randomised, 52-week, phase III, double-blind, parallel-treatment trial. Lancet. 2009;373:473-81.

54. Zinman B, Gerich J, Buse J, et al. Efficacy and safety of the human glucagon-like peptide-1 analog liraglutide in combination with metformin and thiazolidinedione in patients with type 2 diabetes (LEAD-4 Met+TZD). Diabetes Care. 2009;32:1224-30.

55. Russell-Jones D, Vaag A, Schmitz O, et al. Liraglutide vs insulin glargine and placebo in combination with metformin and sulfonylurea therapy in type 2 diabetes mellitus (LEAD-5 met+SU): a randomised controlled trial. Diabetologia. 2009;52:2046-55.

56. Marso SP, Lindsey JB, Stolker JM, et al. Cardiovascular safety of liraglutide assessed in a patient-level pooled analysis of phase 2: 3 liraglutide clinical development studies. Diab Vasc Dis Res. 2011;8: 237-40.

57. George M, Rajaram M, Shanmugam E. New and emerging drug molecules against obesity. J Cardiovasc Pharmacol Ther. 2014;19: 65-76.

58. Astrup A, Madsbad S, Breum L, et al. Effect of tesofensine on bodyweight loss, body composition, and quality of life in obese patients: a randomised, double-blind, placebo-controlled trial. Lancet. 2008;372:1906-13.

59. Orexigen Therapeutics Inc. Orexigen receives three month extension of FDA NB32. 2014:1-2. Available at: http://ir.orexigen.com/ phoenix.zhtml?c=207034\&p=irol-newsArticle\&ID=1938944. Accessed 15 Oct 2014.

60. Jackson VM, Price DA, Carpino PA. Investigational drugs in phase II clinical trials for the treatment of obesity: implications for future development of novel therapies. Expert Opin Investig Drugs. 2014;23:1055-66.

61. Gadde KM, Yonish GM, Foust MS, et al. Combination therapy of zonisamide and bupropion for weight reduction in obese women: a preliminary, randomized, open-label study. 2007;1227-30.

62.• Orexigen Therapeutics Inc. Emaptic. 2014. Available at: http:// www.orexigen.com/programs/empatic.html. Accessed 26 Nov 2014. This web page outlined some of the only available data on the effectiveness of Empatic (bupropion-zonisamide slow-release compound) a promising weight management medication undergoing phase III clinical testing.

63. Ravussin E, Smith SR, Mitchell JA, et al. Enhanced weight loss with pramlintide/metreleptin: an integrated neurohormonal approach to obesity pharmacotherapy. 2009;17:1736-43.

64. Tam CS, Lecoultre V, Ravussin E. Novel strategy for the use of leptin for obesity therapy. Expert Opin Biol Ther. 2011;11:167785.

65. PR Newswire, source Amylin Pharmaceuticals Inc. Amylin Pharmaceuticals Announces Positive Results from Dose-Ranging Clinical Study of Pramlintide/Metreleptin Combination Treatment for Obesity. 2009. Available at: http://www.prnewswire.com/newsreleases/amylin-pharmaceuticals-announces-positive-results-fromdose-ranging-clinical-study-of-pramlintidemetreleptincombination-treatment-for-obesity-62158697.html. Accessed 16 Mar 2014. 